\title{
Formaçáo docente sob a perspectiva da complexidade: um olhar sobre impactos nos distúrbios musculoesqueléticos e na qualidade de vida dos professores
}

\author{
Ricelli Endrigo Ruppel da Rocha \\ https://orcid.org/0000-0002-4277-1407 \\ Kênia Paulino de Queiroz Souza ${ }^{2}$ \\ https://orcid.org/0000-0002-7352-824X \\ Antonio Pantoja Vallejo ${ }^{3}$ \\ https://orcid.org/0000-0001-5374-4378
}

\section{Resumo}

O objetivo desta pesquisa foi analisar os impactos do programa pautado na perspectiva da complexidade sobre os distúrbios musculoesqueléticos e a qualidade de vida de docentes. Participaram da pesquisa 193 docentes do sexo feminino da Educação Infantil e do Ensino Fundamental de escolas da rede municipal de educação de três municípios de Santa Catarina. Os participantes foram divididos em dois grupos: o Grupo $1(\mathrm{n}=100)$ foi composto por professoras que não participaram do programa, e o Grupo $2(n=93)$, por professoras que participaram do programa de formaçâo continuada durante 2 anos. O Questionário Nórdico de Sintomas Osteomusculares foi utilizado para avaliar os distúrbios musculoesqueléticos, e o questionário WHOQOL-bref, para avaliar a qualidade de vida. Os resultados mostraram que as partes superior e inferior das costas, o pescoço, os ombros, os punhos e as mãos foram as regiōes mais acometidas pelos distúrbios musculoesqueléticos em ambos os grupos. Quando comparados os distúrbios musculoesqueléticos entre os grupos, as professoras do Grupo 1 apresentaram maior frequência nos 7 dias que antecederam a pesquisa $(16,4 \%)$ que as professoras do Grupo $2(10,7 \%)(\mathrm{p}<0,05)$. Na comparação da percepção da qualidade de vida

1 Professor Doutor do Programa de Mestrado Profissional em Educação Básica e do Programa de Mestrado Acadêmico em Desenvolvimento e Sociedade da Universidade Alto Vale do Rio do Peixe (UNIARP), Caçador, Brasil. E-mail: ricellie@uniarp.edu.br.

2 Professora Doutora da Universidade Estadual do Tocantins (UNITINS). Membro do Grupo de Pesquisa em Rede Internacional Investigando Escolas Criativas e Inovadoras e da Rede Internacional de Escolas Criativas (RIEC). E-mail: keniaqueiroz06@hotmail.com.

${ }^{3}$ Professor Titular da Universidade de Jaén (UJA), Espanha. Coordenador do Grupo de Investigación IDEO (HUM 660), Página web: www.antoniopantoja.es. Email: apantoja@ujaen.es. 
entre os grupos, o Grupo 2 apresentou melhores escores na mediana de domínio Físico $(\mathrm{p}<0,05)$, Psicológico $(\mathrm{p}<0,01)$, Social $(0,05)$ e Ambiental $(0,001)$ quando comparado ao Grupo 1. A percepção da qualidade de vida geral (QV geral) foi melhor nas professoras do Grupo 2 quando comparada ao Grupo 1 ( $\mathrm{p}<0,001)$. Em resumo, o programa de FormaçãoAção em Escolas Criativas melhorou a saúde e a qualidade de vida de docentes da Educação Básica.

Palavras-chave: Complexidade, Formação, Docentes, Dor musculoesquelética, Qualidade de vida.

\title{
Teacher's formation under the perspective of complexity: a view over the impacts of musculoskeletal diseases and the teachers' quality of life
}

\begin{abstract}
The aim of this research was to analyze the impact of the program based on the perspective of complexity about the musculoskeletal diseases and the teachers' quality of life. One hundred and ninety-three female teachers of Children and Elementary School from 3 towns in Santa Catarina took part in the research. The participants were divided into 2 groups, Group 1 $(\mathrm{n}=100)$ were made by teachers who did not take part in the program and Group 2 ( $n=93)$ by the ones who took part in the continuing program for 2 years. The Nordic Questionnaire of Musculoskeletal Symptoms was used to evaluate the Musculoskeletal Diseases and the WHOQOL-bref questionnaire to measure the quality of life. The results showed that the upper and the lower part of the back, neck, shoulders, and fists/hands were the most affected regions by the musculoskeletal diseases in both groups. When the musculoskeletal diseases are compared between the groups, the teachers in Group 1 showed higher frequency in the last 7 days which preceded the research $(16.4 \%)$ compared to the teachers in Group $2(10.7 \%)$ $(\mathrm{p}<0.05)$. In comparison with the perception of the quality of life between the groups, Group 2 showed better scores in the average of Physical domain $(\mathrm{p}<0.05)$, Psychological $(\mathrm{p}<0.01)$, Social Relations (0.05) and Environment (0.001) compared to Group 1. The perception of the quality of life in general (general QL) was better among the teachers in Group 2 when compared to Group 1 (0.001). To sum up, the Formation-Action in Creative Schools improved the health and quality of life of the Elementary School teachers.
\end{abstract}

Keywords: Complexity, Formation, Teachers, Musculoskeletal pain, Quality of life.

\section{Introduçáo}

A formação docente tem requisitado investimentos para transformar iniciativas atomizadas e descontextualizadas em possibilidades que se sustentem pelos vieses da complexidade, da transdisciplinaridade e da ecoformação. A perspectiva deste estudo é transitar por uma iniciativa formativa ancorada nesses três conceitos. 
Parte-se do princípio de que a formação precisa promover alternativas flexíveis e interligadoras capazes de articular os saberes curriculares às demandas das realidades local e global. Isso implica uma dimensão formativa comprometida com a superação do pensar e do fazer reducionista e simplificador.

Gatti, Barreto e André (2011) defendem a necessidade de reflexão sobre os referenciais de formação continuada que vêm sendo implantados, especialmente os centrados em uma perspectiva transmissiva que priorizam palestras, seminários, oficinas e cursos rápidos. Essa preocupação converge com as reflexóes de Moraes (2012) a respeito da necessidade de se pensar na problemática educacional integralmente, evitando a utilização de discursos românticos e a valorizaçáo de iniciativas formativas fragmentadas.

Pautando-se em demandas como essas e na incerteza em relação ao futuro da humanidade, o Programa de Formação-Ação em Escolas Criativas tem sido dinamizado. Ele foi elaborado a partir de reflexôes sobre as Escolas Criativas (TORRE, 2009), tendo sido impulsionado no contexto brasileiro com o lançamento da obra 'Uma escola para o século XXI: Escolas Criativas e resiliência na educação' (ZWIEREWICZ; TORRE, 2009).

A pesquisa ora apresentada teve como objetivo analisar dados sobre distúrbios musculoesqueléticos e qualidade de vida de docentes que frequentam o referido programa, confrontando-os com os diagnosticados em docentes que não participam da proposta formativa. Trata-se, portanto, de uma pesquisa descritiva e comparativa, com delineamento transversal e abordagem quantitativa.

A preocupação em aproximar a formação a questôes relacionadas à saúde docente é justificada pelos resultados de pesquisas precedentes, que evidenciam o quanto os profissionais da área educacional são acometidos por problemas que impedem ou dificultam sua atuação. Entre esses estudos, consta o de Shuai et al. (2014), indicando que os distúrbios musculoesqueléticos (DME) representam a segunda maior causa de problemas de saúde na populaçáo trabalhadora, afetando de $50 \%$ a $80 \%$ dessa população em todo o mundo.

Especificamente no contexto brasileiro, 39\% a 95\% dos docentes são acometidos por DME, constituindo um grande problema de saúde pública (ERICK; SMITH, 2011). Além disso, esses problemas impactam na qualidade de vida dos docentes e em sua satisfaçáo com o trabalho, 
aumentando também os afastamentos das atividades laborais (ABDULMONEM et al., 2014). Por isso se justifica o interesse em conhecer os efeitos de uma proposta formativa que se definiu com base no propósito de colaborar para o bem-estar individual, social e ambiental, respaldando-se na tríade conceitual "complexidade-transdisciplinaridade-ecoformação".

\section{Complexidade, transdisciplinaridade e ecoformaçáo como conceitos superadores de formaçóes atomizadas e descontextualizadas}

Pautar a formação docente na tríade "complexidadetransdisciplinaridade-ecoformação" significa dar sentido às conexôes entre o ser humano, a sociedade e seu entorno. Trata-se de uma tríade fulcral para se repensar a formação docente atomizada e descontextualizada de condiçóes que afetam os docentes no que diz respeito à sua saúde física e mental.

Destarte, depois de séculos de um pensamento reducionista e simplificador que afeta a formação docente, requisitam-se esforços para se superar a compreensão da realidade a partir de um olhar disjuntivo. Como uma das possíveis vias, o pensamento complexo favorece a religaçáo dos saberes que foram separados por disciplinas e que, cada vez mais, isolam-se por meio da hiperespecialização (MORIN, 2001), afetando tanto o ensino e a aprendizagem como a própria formação dos docentes de Educação Básica e Ensino Superior.

A esse respeito, Morin (2001, p. 121) explica que "[...] o pensamento simples resolve os problemas simples sem problemas de pensamento. O pensamento complexo não resolve ele próprio os problemas, mas constitui uma ajuda à estratégia que pode resolvê-los".

Uma formaçáo que pensa e se desenvolve com o objetivo de considerar apenas a dimensão cognitiva, sem envolver o ser humano a partir de suas multidimensionalidades, a sociedade e a natureza caracteriza um percurso reducionista. Em contrapartida, os princípios do pensamento complexo buscam superar o pensamento simplificador. Esses princípios são “[...] algumas ferramentas intelectuais necessárias para aprender a pensar de forma complexa, a apreender e a compreender o complexo, ou seja, 'o que está tecido junto’. [...] Tais princípios são também chamados de operadores cognitivos para um pensar complexo" (MORAES, 2019, p. 107). 
Morin (2001) apresenta princípios cujas características são complexas e fornecem ferramentas para compreender vários contextos e situaçóesproblema que fazem parte da vida planetária, são eles: sistêmico ou organizacional, hologramático, retroativo, recursivo, autonômico/dependente, dialógico e de reintrodução do sujeito cognoscente. Além disso, mesmo que cada um tenha suas especificidades, existe uma complementaridade entre eles, pois em algum momento se encontram, dialogam, não se colocando de modo contrário.

Junto ao constante movimento metodológico de tais princípios para contribuir com estratégias que facilitem a compreensão do pensamento complexo e do aprender a pensar complexo, a transdisciplinaridade constituise em uma condição imprescindível. Isso ocorre pois ela representa o que Nicolescu (2014) indica que está entre quaisquer disciplinas, através e além delas, sendo que seu objetivo é a "[...] compreensão do mundo presente, para o qual um dos imperativos é a unidade do conhecimento" (NICOLESCU, 1999, p. 51, grifo nosso).

A transdisciplinaridade pode ser definida como a busca do sentido da vida por meio de relaçóes entre os diversos saberes (SANTOS, 2009). Por isso, é concebida como uma postura, um espírito integrador diante do saber, uma vocação articuladora para a compreensão da realidade sem abandonar o respeito pelas áreas do conhecimento e seu devido rigor (NICOLESCU, 2005).

O pensamento complexo e sua dinamização, feita por meio de uma perspectiva formativa transdisciplinar, são potencializados quando trabalhados de forma articulada com a ecoformação. Assim, a ecoformação "[...] acontece a partir de uma fenomenologia complexa e transdisciplinar que considera o sujeito em sua multidimensionalidade, inserido em um contexto social, ecológico e espiritual, mediado pela cultura que o rodeia e com a qual interage constantemente" (MORAES, 2019, p. 119-120), com enfoque nas relaçôes do ser humano com seu entorno vital (NAVARRA, 2008).

Uma proposta formativa pautada nessa tríade conceitual valoriza um olhar atento sobre a condição docente, suas relaçóes e seu entorno. Isso significa um olhar amplo, profundo, mas também personalizado, para que cada docente encontre possibilidades de religar sua profissionalização a uma prática formativa articulada local e globalmente, individual e socialmente. 
Esse é o foco do Programa de Formação-Ação em Escolas Criativas, uma iniciativa que tem entre seus objetivos: estimular o desenvolvimento de práticas pedagógicas transdisciplinares e ecoformadoras; ampliar o protagonismo de docentes e estudantes; ampliar a criação de cenários de aprendizagem e de materiais didáticos alternativos; favorecer o envolvimento de situações-problema e o desenvolvimento de açôes que estimulem o bemestar individual, social e ambiental (ZWIEREWICZ, 2017).

Depois de uma experiência piloto, o Programa de Formação-Ação em Escolas Criativas foi ofertado pela primeira vez na cidade de Gravatal (Santa Catarina), em 2009, e envolveu gestores e docentes das redes municipal e estadual de ensino (ALMEIDA, 2018). Divulgada internacionalmente devido aos resultados alcançados, Torre e Zwierewicz (2009) afirmam que a experiência serviu como referência para as formaçóes subsequentes por demonstrar o valor de uma educação a partir da vida e para a vida.

Ao sistematizar o histórico do Programa de Formação-Ação em Escolas Criativas, Zwierewicz (2018) destaca que, no decorrer de sua implementação, contabilizou-se um total de dez municípios que estimularam a participação de gestores e docentes no programa: sete deles disponibilizando-o para todos os docentes de sua rede municipal (Balneário Rincão, Grão-Pará, Gravatal, São Ludgero, Paulo Lopes, Santa Rosa de Lima e Timbó Grande); outros dois envolveram, prioritariamente, algumas de suas instituiçóes de ensino (Caçador e Urussanga). Além disso, o programa foi desenvolvido em momentos pontuais em três escolas da rede estadual de ensino de Santa Catarina, em Braço do Norte, Santa Rosa de Lima e Urussanga. Ele está sendo desenvolvido atualmente no município de União da Vitória (Paraná).

\section{Método}

Neste estudo descritivo e comparativo, com delineamento transversal e abordagem quantitativa, participaram da pesquisa 193 professores do sexo feminino que trabalham na rede municipal de educação e que estavam em plena docência no Ensino Infantil e Fundamental dos municípios de Paulo Lopes, São Ludgero e Caçador, localizados no estado de Santa Catarina. As professoras foram divididas em 2 grupos: o Grupo 1 ( $n=100)$ foi formado por professoras do município de Caçador que não participaram de um Programa de Formação-Ação em Escolas Criativas; o Grupo 2 ( $\mathrm{n}=93$ ) 
constituiu-se de professoras dos municípios de Paulo Lopes e São Ludgero que participaram durante dois anos de um Programa de Formação-Ação em Escolas Criativas.

O programa tem sido oferecido como possibilidade de formação continuada a gestores e docentes que atuam na Educação Básica. Teoricamente, a proposta formativa trabalha com uma perspectiva transdisciplinar e ecoformadora, articulando teoria e prática e estimulando a aproximação do conteúdo à realidade, por meio de uma metodologia inovadora e que valoriza o protagonismo docente (ZWIEREWICZ et al., 2016).

Como critério de inclusão para participar da pesquisa, os docentes do Grupo 1 não poderiam estar inseridos em nenhum programa de formação continuada nos dois anos que antecederam a pesquisa. Para o Grupo 2, o critério de inclusão foi ter participado ativamente do respectivo programa de formação continuada, com frequência mínima de $80 \%$ durante os dois anos de formação.

Para a realização do estudo, foi solicitada uma autorização aos secretários de educação dos municípios. Em seguida, os docentes do Grupo 1 e do Grupo 2 foram informados sobre os procedimentos, e somente participaram os profissionais que assinaram o Termo de Consentimento Livre e Esclarecido (TCLE). A pesquisa foi aprovada pelo Comitê de Ética em Pesquisa da Universidade Alto Vale do Rio Peixe (UNIARP), atendendo, portanto, os preceitos éticos implicados em pesquisas que envolvem seres humanos.

A coleta de dados do Grupo 1 foi realizada nos meses de outubro e novembro de 2018, durante o período letivo, e a do Grupo 2 foi realizada ao final dos dois anos de formação continuada. Para avaliar os distúrbios musculoesqueléticos, foi utilizado o Questionário Nórdico de Sintomas Osteomusculares (QNSO), composto por uma figura humana dividida em nove regióes anatômicas, adaptado culturalmente para a língua portuguesa por Barros e Alexandre (2003). O respondente deveria relatar a ocorrência dos sintomas considerando tanto os 12 meses como os sete dias precedentes à entrevista, além da ocorrência de afastamento das atividades rotineiras no último ano (PINHEIRO; TRÓCCOLI; CARVALHO, 2002).

Para avaliar a qualidade de vida, foi utilizado o questionário WHOQOL-bref, da World Health Organization Quality of Life Group 
(Grupo de Qualidade de Vida da Organização Mundial da Saúde), proposto por Fleck et al. (2000), que consiste em 26 questôes, duas gerais sobre a satisfaçáo com a saúde e a qualidade de vida e outras 24 correspondentes a quatro domínios (físico, psicológico, social e ambiental). O domínio físico refere-se a informaçóes sobre dor e desconforto, energia e fadiga, mobilidade, necessidade de assistência médica etc.; o psicológico diz respeito a afeto, à memória, concentração, autoestima, imagem corporal e aparência; o social investiga as relaçóes interpessoais e as redes de apoio social; e o ambiental trata de questôes relativas à segurança física, proteção, aos recursos financeiros, ao transporte, à moradia, entre outras. Os resultados dos escores brutos de cada faceta foram transformados em um escore de variação de 0 a 100 pontos. Esta transformação possibilitou expressar o escore da escala percentual entre o valor mais baixo possível (0) e o mais alto possível (100).

Inicialmente foi realizada a análise descritiva dos dados, e os resultados foram apresentados com média, mediana, mínimo, máximo, frequência (\%) e desvio padrão $(\mathrm{Dp})$. Para determinar a estatística paramétrica ou não paramétrica, foi verificada a normalidade dos dados com o teste de ShapiroWilk e o teste de Levene, para analisar a homogeneidade das variáveis entre os grupos. Com a normalidade dos dados apresentados nos DME, foi utilizado o teste "T" de Students para amostras independentes para comparar os grupos. Nas análises da percepção da qualidade, devido à falta de normalidade dos dados, foi utilizado o teste de Mann-Whitney para comparar os grupos e o teste de Kruskal Wallis para comparar os domínios dentro dos grupos. Quando efeitos significativos foram detectados, análises post hoc foram realizadas utilizando o teste de Dunn. O nível de significância adotado foi de $\mathrm{p}<0,05$.

Para a análise dos resultados da qualidade de vida dos docentes, foi utilizado o modelo estatístico adotado pelo WHOQOL-bref, segundo o método e os resultados de grupos focais no Brasil (FERRAZ et al., 2002). Todas as análises foram realizadas no Statistical Package for the Social Sciences (SPSS), versão 22.0.

\section{Resultados}

Os resultados da Tabela 1 mostraram que as regióes anatômicas mais acometidas pelos DME nas professoras do Grupo 1 e do Grupo 2 foram as 
partes superior e inferior das costas, o pescoço, os ombros e os punhos/ as mãos. Quando comparados os grupos, apesar de o Grupo 1 apresentar maior frequência de DME $(34,1 \%)$ do que o Grupo 2 (28,8\%), não houve diferença significativa entre os grupos nos 12 meses que antecederam a pesquisa.

Com relação ao impedimento de realizar atividades laborais e diárias nos últimos 12 meses por algum problema relacionado aos DME (Tabela 1), 9,1\% das professoras do Grupo 1 e 6,6\% do Grupo 2 foram impedidas, entretanto não houve diferença significativa entre eles ( $p>0,05)$. Contudo, nos sete dias que antecederam a pesquisa, as professoras do Grupo 1 mostraram maior frequência de DME $(16,4 \%)$ quando comparadas às professoras do Grupo $2(10,7 \%)(\mathrm{p}<0,05)$.

Tabela 1. Prevalência de distúrbios musculoesqueléticos e incapacidade funcional do Grupo de Professores que não participou do Programa de Formação-Ação em Escolas Criativas (Grupo 1) e do Grupo de Professores que participou do Programa de Formação-Ação em Escolas Criativas (Grupo 2).

\begin{tabular}{|c|c|c|c|c|c|c|}
\hline \multirow[b]{2}{*}{ Região Anatômica } & \multicolumn{3}{|c|}{ Grupo 1} & \multicolumn{3}{|c|}{ Grupo 2} \\
\hline & $\begin{array}{c}\text { Sintomas nos } \\
\text { últimos } 12 \\
\text { meses (\%) }\end{array}$ & $\begin{array}{c}\text { Impedido } \\
\text { de realizar } \\
\text { atividades } \\
\text { nos últimos } \\
12 \text { meses } \\
\text { (\%) }\end{array}$ & 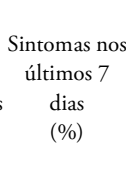 & $\begin{array}{c}\text { s Sintomas nos últimos } 12 \\
\text { meses } \\
(\%)\end{array}$ & $\begin{array}{l}\text { Impedido de realizar } \\
\text { atividades nos } \\
\text { últimos } 12 \text { meses } \\
(\%)\end{array}$ & $\begin{array}{c}\text { Sintomas } \\
\text { nos } \\
\text { últimos } \\
7 \text { dias } \\
(\%)\end{array}$ \\
\hline Pescoço & 40,4 & 6,5 & 19,7 & 33,0 & 7,4 & 11,7 \\
\hline Ombros & 42,7 & 10,2 & 21,6 & 38,3 & 10,6 & 11,7 \\
\hline Costas superior & 42,7 & 11,7 & 21,4 & 39,4 & 6,4 & 17,0 \\
\hline Cotovelos & 14,6 & 3,3 & 6,0 & 7,4 & 2,1 & 5,3 \\
\hline Punhos/ máos & 42,3 & 13,0 & 20,5 & 31,9 & 6,4 & 8,5 \\
\hline Costas inferior & 44,9 & 14,0 & 22,9 & 51,1 & 12,8 & 17,0 \\
\hline Quadril/ coxas & 22,0 & 8,0 & 10,9 & 14,9 & 3,2 & 7,4 \\
\hline Joelhos & 26,6 & 9,9 & 11,5 & 23,4 & 6,4 & 8,5 \\
\hline Tornozelos/ pés & 30,9 & 5,8 & 13,6 & 20,2 & 4,3 & 9,6 \\
\hline Média $\pm \mathrm{Dp}$ & $34,1 \pm 10,9$ & $9,1 \pm 3,5$ & $16,4 \pm 6,0$ & $28,8 \pm 13,6$ & $6,6 \pm 3,4$ & $10,7 \pm 4,0$ \\
\hline
\end{tabular}

Fonte: Elaborada pelos autores (2020).

Nos domínios da qualidade de vida (Tabela 2), os melhores escores na mediana das professoras do Grupo 1 foram os domínios psicológico $(62,5 \%)$ e social (66,7\%). Nas professoras do Grupo 2, os domínios social (75,0\%), ambiental $(68,8 \%)$ e psicológico $(66,7)$ tiveram os melhores escores na mediana. 
Quando comparados no Grupo 1 os domínios com melhor e pior escore na mediana (social e psicológico com físico e ambiental), os resultados mostraram que houve diferença entre os domínios $(\mathrm{p}<0,05)$. Na comparação dos domínios com melhor e pior escore na mediana (social, ambiental e psicológico versus físico e ambiental) do Grupo 2, foram observadas diferenças significativas do domínio físico em relação aos demais $\mathrm{p}<0,05)$.

$\mathrm{Na}$ comparação da percepção da qualidade de vida entre os grupos (Tabela 2), o Grupo 2 apresentou melhores escores na mediana de domínio físico $(\mathrm{p}<0,05)$, psicológico $(\mathrm{p}<0,01)$, social $(0,05)$ e ambiental $(0,001)$ quando comparado ao Grupo 1. Além disso, na percepção da qualidade de vida geral (QV geral), o escore da mediana das professoras do Grupo 2 foi significativamente maior do que o escore da mediana do Grupo $1(0,001)$.

Tabela 2. Resultados da percepçáo da qualidade de vida em cada domínio do WHOQOL-BRIEF e da qualidade de vida geral (QV) do grupo de professores que não participou do Programa de Formação-Ação em Escolas Criativas (Grupo 1) e do grupo de professores que participou do Programa de Formação-Ação em Escolas Criativas (Grupo 2).

\begin{tabular}{lcccccc}
\hline \multirow{2}{*}{ Domínios } & \multicolumn{3}{c}{ Grupo 1 } & \multicolumn{3}{c}{ Grupo 2 } \\
\cline { 2 - 7 } & Mediana & Mínimo & Máximo & Mediana & Mínimo & Máximo \\
\hline Físico & 53,6 & 10,7 & 75,0 & 60,7 & 42,9 & 78,6 \\
Psicológico & 62,5 & 20,8 & 100,0 & 66,7 & 45,8 & 87,5 \\
Social & 66,7 & 25,0 & 100,0 & 75,0 & 41,7 & 100,0 \\
Ambiental & 56,3 & 21,9 & 90,6 & 68,8 & 40,6 & 84,4 \\
\hline QV Geral & 59,0 & 25,9 & 89,7 & 67,7 & 44,0 & 84,1 \\
\hline
\end{tabular}

Fonte: Elaborada pelos autores (2020).

\section{Discussáo}

Nesta pesquisa, as regióes anatômicas com maior frequência de DME nos professores de ambos os grupos foram as partes superior e inferior das costas, o pescoço, os ombros e os punhos/ as mãos (Tabela 1). Esses resultados corroboram com outras pesquisas nacionais e internacionais que avaliaram os DME em professores que atuam na educação básica (CARVALHO; ALEXANDRE, 2006; CARDOSO et al., 2009; BRANCO; JANSEN, 2011; FERNANDES; ROCHA; FAGUNDES, 2011; RIBEIRO et al., 2011; MANGO et al., 2012; CEZÁR-VAZ et al., 2013; KARAKAYA et al., 2015; CEBALLOS; SANTOS, 2015; SILVA; DUTRA, 2016; ROCHA et al., 2017; SOLIS-SOTO et al., 2017; NG; VOO; MAAKIP, 2019). 
As possíveis razóes para os DME acometerem as regióes anatômicas citadas nos professores podem estar relacionadas às posturas inapropriadas durante as atividades laborais, ao excesso de peso ao transportar materiais para a escola, à ergonomia inadequada do mobiliado, à baixa capacidade funcional, ao sedentarismo e a muitas horas em pé (CARDOSO et al., 2009; RIBEIRO et al., 2011; BRANCO; JANSEN, 2011; CEZAR-VAZ et al., 2016).

Com relação à frequência geral de DME nas professoras do Grupo 1 $(34,1 \%)$ e do Grupo $2(16,4 \%)$ nos 12 meses que antecederam a pesquisa, observa-se que está abaixo de outros estudos. Por exemplo, em uma revisão sistemática com 13 países (três da América, quatro da Europa, cinco da Ásia e Austrália), a prevalência de distúrbios musculoesqueléticos nos professores ficou entre 40\% e 50\% (TEMESGEN et al., 2019). Outro estudo em diversos países, incluindo o Brasil, mostrou que 39\% a 95\% dos professores são acometidos por problemas musculoesqueléticos (ERICK; SMITH, 2011).

É importante destacar que, apesar de não ter havido diferença significativa na frequência média de DME entre os grupos, as professoras que participaram do Programa de Formação-Ação em Escolas Criativas (Grupo 2) apresentaram menor frequência geral de DME, e isso pode estar relacionado ao processo de formaçáo continuada. Por trabalhar a partir de uma perspectiva transdisciplinar e ecoformadora, comprometida com o estímulo ao trabalho colaborativo, a pertinência do ensino, a resiliência e a valorização do protagonismo dos implicados, utilizando uma metodologia inovadora, esperase que o programa melhore o bem-estar dos docentes (ZWIEREWICZ et al., 2016) e, com isso, diminua sintomas de dor e desconforto.

Nesta pesquisa, houve uma baixa frequência de professoras que foram impedidas de realizar as atividades diárias por apresentar algum DME, principalmente no Grupo 2, que participou da formação continuada (Tabela 1). Como citado anteriormente, a formação continuada numa perspectiva transdisciplinar e ecoformadora estimula a resiliência, podendo aumentar a capacidade de os professores lidarem com problemas, adaptarem-se a mudanças, superarem obstáculos ou resistirem à pressão de situaçóes adversas durante as atividades laborais.

Destaca-se que, os DME nas professoras do Grupo 2 nos sete dias que antecederam a pesquisa foram menos expressivos que os DME nas professoras do Grupo 1 (Tabela 1). Inferimos que, por estimular o protagonismo e a resiliência docente, o Programa de Formação-Ação pode intensificar o 
desenvolvimento do autocuidado com a saúde, produzindo melhores estratégias de prevenção a doenças e maior capacidade dos professores de manter a qualidade do ensino. Isso é importante porque os DME impactam negativamente a qualidade de vida desses profissionais, acarretando efeitos indesejáveis no rendimento dos estudantes, uma vez que as dificuldades sentidas pelos docentes refletem na qualidade de suas práticas pedagógicas, reduzindo as potencialidades de aprendizagem (SCHEUCH; HAUFE; SEIBT, 2015).

Os resultados desta pesquisa, nos domínios da qualidade de vida, mostraram que as professoras que participaram de um programa de formação (Grupo 2) tiveram melhores escores nos domínios social, psicológico e ambiental, enquanto as professoras que não participaram de um programa de formação continuada (Grupo 1) tiveram os melhores escores (Tabela 2) nos domínios social e psicológico. Os resultados obtidos neste estudo são semelhantes a outras pesquisas que avaliaram a qualidade de vida de professores da Educação Básica com o WHOQOL-bref, mostrando que os docentes estáo mais satisfeitos com relaçóes pessoais, apoio social, capacidade de trabalho, autoestima, aparência e imagem corporal, aspectos cognitivos como aprendizagem e memória, oportunidades de adquirir novos conhecimentos, lazer e recursos financeiros (SANTOS; ESPINOSA; MARCON, 2020; ROCHA et al., 2017; PEREIRA et al., 2014; PEREIRA; TEIXEIRA; LOPES, 2013).

É importante ressaltar que o domínio físico - relacionado a condições de dor e desconforto, energia e fadiga, mobilidade, necessidade de assistência médica - obteve o menor escore em ambos os grupos. Esse resultado pode estar relacionado à frequência elevada de DME, pois a presença desses problemas pode causar dores e fadiga muscular, impactando negativamente a qualidade de vida das docentes (NG; VOO; MAAKIP, 2019).

$\mathrm{Na}$ comparação entre os grupos nos domínios da qualidade de vida, no Grupo 2, que participou do Programa de Formação-Ação em Escolas Criativas, todos os escores foram melhores do que no Grupo 1, que não participou do programa (Tabela 2).

Pautando-se na tríade conceitual pensamento complexo, transdisciplinaridade e ecoformação, o Programa de Formação-Ação em Escolas Criativas é desenvolvido em etapas que estimulam a conexão com a realidade dos docentes participantes e de seus contextos de atuação, 
priorizando o estímulo ao trabalho colaborativo, a pertinência do ensino, a resiliência e a valorização do protagonismo dos implicados, utilizando uma metodologia inovadora em seu desenvolvimento, além de estimular que os docentes utilizem um processo aproximado em sala de aula (ALMEIDA; ZWIEREWICZ; CARREÑO, 2019, p. 97). Esse processo pode melhorar a formação e a motivação dos docentes, impactando na melhoria da percepção da saúde e da qualidade de vida. Os escores da percepção da qualidade de vida geral do Grupo 2 foram melhores que do Grupo 1 (Tabela 1). Enfatizamos que o programa de formação continuada pode ter sido responsável por esses resultados, pois a qualidade de vida é decorrente de uma construção subjetiva e multidimensional, influenciada por diversos fatores como longevidade, satisfação no trabalho e realização pessoal, salário, lazer, relaçôes familiares, disposição, qualidade nos relacionamentos, opçóes de lazer, acesso a eventos culturais, espiritualidade, entre outros (PEREIRA et al., 2014; PEREIRA; TEIXEIRA; LOPES, 2013).

\section{Consideraçóes finais}

O programa de formação-ação tem demonstrado que novas formas de pensar e trabalhar nas escolas se estabelecem a partir da mudança de pensamento. Nesse processo, a percepção, os objetivos, as intenções mudam em convergência com a criação de possibilidades para a valorizar o desenvolvimento integral, estimulado a partir de práticas pedagógicas comprometidas com o bem-estar individual, social e ambiental.

Essas alternativas são criadas para superar a priorização do âmbito intelectual em detrimento de outras dimensóes que integram o desenvolvimento humano, entre elas a emocional e a relacional. Também são alternativas para interligar os processos de ensino e de aprendizagem às demandas sociais e ambientais, viabilizando o trabalho com conteúdos vivos e comprometendo as práticas pedagógicas com as demandas da realidade atual, com atenção especial às incertezas em relação ao futuro.

Com esse olhar, esta pesquisa teve como objetivo analisar os impactos do Programa de Formação-Ação em Escolas Criativas sobre os distúrbios musculoesqueléticos e a qualidade de vida de docentes. Os dados coletados com os docentes que participaram do Programa formação-ação e sua 
comparação com os que não passaram por essa experiência elucidam a relevância de vincular formação e bem-estar docente.

Foram obtidos resultados positivos na percepção da qualidade de vida entre os grupos, comprovando que os docentes que participaram da formaçáo apresentaram melhores índices na mediana do domínio físico, psicológico, social e ambiental. Isso evidencia a relevância de considerar questóes individuais, sociais e ambientais nos encontros formativos. Esse processo é possível quando se implica nas propostas formativas a tríade conceitual "complexidade-trandisciplinaridade-ecoformação".

O escore mais elevado sobre a percepção da qualidade de vida geral obtido pelos docentes que participaram da formação em relação aos que não participaram acentua o valor da ecoformação, pois esta trabalhada de forma articulada à autoformação e à heteroformação. Ele traduz as atividades formativas em possibilidades para o autoconhecimento e para a valorização de si e das relaçóes estabelecidas com os outros e com o entorno.

O mesmo pode ser observado na comprovaçáo de que os docentes que participaram do Programa de Formação-Ação em Escolas Criativas apresentaram menor frequência geral de DME de modo geral e nos sete dias que antecederam a pesquisa. Nesse sentido, vale lembrar que o trabalho articulado da ecoformação com o pensamento complexo e as práticas transdisciplinares acentua possibilidades para que os docentes revelem seu potencial criativo, situando-se como protagonistas de um ensino inovador, além de acentuar sua resiliência no enfrentamento de adversidades surgidas na transição de práticas tradicionais para alternativas que promovam um diálogo entre as disciplinas e dessas com a realidade.

Com base nos resultados deste estudo sobre distúrbios musculoesqueléticos e qualidade de vida docente, evidencia-se a relevância de novas possibilidades investigativas. Sáo objetos para possíveis pesquisas as próprias atividades realizadas durante os encontros formativos, bem como as atividades desenvolvidas pelos docentes em sala de aula.

Analisar como essas atividades são planejadas e desenvolvidas por docentes que participam do programa formativo e compará-las com as produzidas por quem não vivenciou esse processo pode ser fundamental para colaborar tanto na formação continuada como no planejamento e na prática pedagógica. Nesse sentido, currículo, formação e bem-estar docente passariam 
a ser triangulados como uma nova questão implicada nas problemáticas das pesquisas.

\section{Referências}

ABDULMONEM, A. et al. The prevalence of musculoskeletal pain \& its associated factors among female Saudi school teachers. Pakistan Journal of Medical Sciences, [s. l.], v. 30, n. 6, p. 1191-6, 2014. Disponível em: https://www.ncbi.nlm.nih.gov/pmc/articles/PMC4320698/pdf/pjms-301191.pdf. Acesso em: 2 abr. 2020.

ALMEIDA, A. L. R. Influência do programa de formação-açâo em escolas criativas na transformação das práticas pedagógicas em uma escola do campo. Dissertação (Mestrado Profissional em Educação Básica) - Universidade Alto Vale do Rio do Peixe, Caçador, 2018.

ALMEIDA, A. L. R.; ZWIEREWICZ, M.; CARREÑO, L. Do Programa de Formação-Ação em Escolas Criativas ao planejamento transdisciplinar e ecoformador em uma escola do campo. Revista Extensáo em Foco, Caçador, v. 7, n. 2, p. 91-107, 2019. Disponível em: https://periodicos.uniarp.edu.br/index.php/extensao/article/view/2164. Acesso em: 20 mar. 2020.

BARROS, E. N. C.; ALEXANDRE, N. M. C. Cross-cultural adaptation of the Nordic musculoskeletal questionnaire. International Nursing Review, [s. l.], v. 50, n. 2, p. 101-108, 2003. Disponível em: https://pubmed.ncbi.nlm.nih.gov/12752909/. Acesso em: 29 mar. 2020.

BRANCO, J. C. J. K.; JANSEN, K. Prevalência de sintomas osteomusculares em professores do ensino fundamental do maior colégio municipal da América Latina. Ciências \& Cognição, [s. l.], v. 16, n. 3, p. 109-115, 2011.

CARDOSO, J. P. et al. Prevalência de dor musculoesquelética em professores. Revista Brasileira de Epidemiologia, [s. l.], v. 12, p. 604-614, 2009. Disponível em: http:/www.scielosp.org/scielo.php?script=sci_arttext\&pid=S1415790X2009000400010\&nrm=iso. Acesso em: 27 mar. 2020.

CARVALHO, A.; ALEXANDRE, N. Sintomas osteomusculares em professores do Ensino Fundamental. Brazilian Journal of Physical Therapy, [s. 
l.], v. 10, p. 35-41, 2006. Disponível em: http://www.scielo.br/scielo.php?script=sci_arttext\&pid=S141335552006000100005\&nrm=iso. Acesso em: 22 mar. 2020.

CEBAlloS, A. G. D. C. D.; SANTOS, G. B. Factors associated with musculoskeletal pain among teachers: sociodemographics aspects, general health and well-being at work. Revista Brasileira de Epidemiologia, [s. l.], v. 18, p. 702-715, 2015. Disponível em: http://www.scielosp.org/scielo.php?script=sci_arttext\&pid=S1415790X2015000300702\&nrm=iso. Acesso em: 2 mar. 2020

CEZÁR-VAZ, M. R. et al. Trastornos musculoesqueléticos en profesores: estudio de enfermería del trabajo. Ciencia y enfermería, [s. l.], v. 19, p. 83-93, 2013. Disponível

em: https://scielo.conicyt.cl/scielo.php?script=sci_arttext\&pid=S071795532013000300009\&nrm=iso. Acesso em: 29 mar. 2020.

ERICK, P. N.; SMITH, D. R. A systematic review of musculoskeletal disorders among school teachers. BMC Musculoskeletal Disorder, [s. l.], v. 12, p. 260, Nov. 2011. Disponível em: https:/www.ncbi.nlm.nih.gov/pmc/articles/PMC3250950/pdf/1471-247412-260.pdf. Acesso em: 4 mar. 2020.

FERNANDES, M. H.; ROCHA, V. M. D.; FAGUNDES, A. A. R. Impacto da sintomatologia osteomuscular na qualidade de vida de professores. Revista Brasileira de Epidemiologia, [s. l.], v. 14, p. 276-284, 2011. Disponível em: http://www.scielosp.org/scielo.php?script=sci_arttext\&pid=S1415790X2011000200009\&nrm=iso. Acesso em: 12 mar. 2020.

FERRAZ, E. V. A. P. et al. Adaptação de questionário de avaliação da qualidade de vida para aplicação em portadores de catarata. Arquivos Brasileiros de Oftalmologia, [s. l.], v. 65, p. 293-298, 2002. Disponível em: http://www.scielo.br/scielo.php?script=sci_arttext\&pid=S0004$27492002000300002 \&$ nrm=iso. Acesso em: 13 mar. 2020.

FLECK, M. P. et al. Aplicação da versão em português do instrumento abreviado de avaliação da qualidade de vida "WHOQOL-bref". Revista de Saúde Pública, [s. l.], v. 34, p. 178-183, 2000. Doi: http://dx.doi.org/10.1590/S0034-89102000000200012. Disponível em: 
http://www.scielo.br/scielo.php?script=sci_arttext\&pid=S003489102000000200012\&nrm=iso. Acesso em: 29 mar. 2020.

GATTI, B. A.; BARRETO, E. S. S.; ANDRÉ, M. E. D. A. Politicas docentes no Brasil: um estado da arte. Brasília: UNESCO, 2011.

KARAKAYA, I. Ç. et al. Musculoskeletal problems and quality of life of elementary school teachers. International Journal of Occupational Safety and Ergonomics, [s. l.], v. 21, n. 3, p. 344-50, 2015. Disponível em: https://dx.doi.org/10.1080/10803548.2015.1035921. Acesso em: 4 mar. 2020.

MANGO, M. S. M. et al. Análise dos sintomas osteomusculares de professores do ensino fundamental em Matinhos (PR). Fisioterapia em Movimento, $[s . \quad$ l. $], \quad$ v. $25, \quad$ p. 785-794, 2012. Disponível em: http://www.scielo.br/scielo.php?script=sci_arttext\&pid=S0103-

51502012000400011\&nrm=iso. Acesso em: 4 mar. 2020.

MORAES, M. C. O Paradigma Educacional Emergente. 16. ed. Campinas: Papirus, 2012.

MORAES, M. C. Saberes para uma cidadania planetária: homenagem a Edgar Morin. Rio de Janeiro: Wak, 2019.

Morin, E. Introdução ao pensamento complexo. 3. ed. Lisboa: Instituto Piaget, 2001.

NAVARRA, J. M. Ecoformação: além da Educação Ambiental. In: TORRE, S. de la; PUJOL, M. A.; MORAES, M. C. (org.). Transdisciplinaridade e ecoformação: um novo olhar sobre a educação. Tradução de Suzana Vidigal. São Paulo: Triom, 2008. p. 235-260.

NG, Y. M.; VOO, P.; MAAKIP, I. Psychosocial factors, depression, and musculoskeletal disorders among teachers. BMC Public Health, [s. l.], v. 19, n. $1, \quad$ p. 234, Feb. 2019. Disponível em: https://www.ncbi.nlm.nih.gov/pmc/articles/PMC6390562/pdf/12889_201 9_Article_6553.pdf. Acesso em: 18 mar. 2020.

NICOLESCU, B. O manifesto da transdisciplinaridade. Tradução de Lucia Pereira de Souza. São Paulo: Triom, 1999. 
NICOLESCU, B. O manifesto da transdisciplinaridade. Tradução de Lucia Pereira de Souza. 3. ed. São Paulo: TRIOM, 2005.

NICOLESCU, B. Transdisciplinariedad: pasado, presente y futuro. In: ESPINOSA MARTINEZ, A. C.; GALVANI, P. (org.). Transdisciplinariedad y formación universitária: teorias y prácticas emergentes. Puerto Vallarta: CEUArkos, 2014. p. 45-90.

PEREIRA, E. F. et al. Elementary school teachers and their quality of life. Revista de Salud Publica, Bogotá, v. 16, n. 2, p. 221-31, 2014. Disponível em: http://www.scielo.org.co/scielo.php?script=sci_arttext\&pid=S012400642014000200006\&lng=en\&nrm=is. Acesso em: 2 abr. 2020.

PEREIRA, E. F.; TEIXEIRA, C. S.; LOPES ADA, S. Quality of life of elementary education teachers in Florianópolis, State of Santa Catarina. Ciência \& Saúde Coletiva, [s. l.], v. 18, n. 7, p. 1963-70, 2013. Disponível em: http://www.scielo.br/scielo.php?script=sci_arttext\&pid=S141381232013000700011\&lng=en\&nrm=iso. Acesso em: 3 abr. 2020.

PINHEIRO, F. A.; TROCCOLI, B. T.; CARVALHO, C. V. Validação do Questionário Nórdico de Sintomas Osteomusculares como medida de morbidade. Rev. Saúde Pública, [s. l.], v. 36, n. 3, p. 307-312, 2002. Doi: https://doi.org/10.1590/S0034-89102002000300008. Disponível em: https://www.scielo.br/scielo.php?pid=S0034-

89102002000300008\&script=sci_abstract\&tlng=pt. Acesso em: 21 jan. 2010.

RIBEIRO, I. D. Q. B. et al. Fatores ocupacionais associados à dor musculoesquelética em professores. Revista Baiana de Saúde Pública, [s. l.], v. 35, n. 1, p. 42-64, 2011. Disponível em: http://files.bvs.br/upload/S/01000233/2011/v35n1/a2097.pdf. Acesso em: 7 abr. 2020.

ROCHA, R. E. R. D. et al. Sintomas osteomusculares e estresse não alteram a qualidade de vida de professores da educação básica. Fisioterapia e Pesquisa, [s. l.], v. 24, p. 259-266, 2017. Disponível em: http://www.scielo.br/scielo.php?script=sci_arttext\&pid=S180929502017000300259\&nrm=iso. Acesso em: 3 abr. 2020.

SANTOS, A. Complexidade e transdisciplinaridade em educação: cinco princípios para resgatar o elo perdido. In: SANTOS, A.; SOMMERMAN, A. 
(coord.). Complexidade e transdisciplinaridade: em busca da totalidade perdida. Porto Alegre: Sulina, 2009. p. 15-38.

SANTOS, E. C.; ESPINOSA, M. M.; MARCON, S. R. Qualidade de vida, saúde e trabalho de professores do ensino fundamental. Acta Paulista de Enfermagem, $\quad$ s. l. $], \quad$ v. 33, 2020. Disponível em: http://www.scielo.br/scielo.php?script=sci_arttext\&pid=S010321002020000100415\&nrm=iso. Acesso em: 13 abr. 2020.

SCHEUCH, K.; HAUFE, E.; SEIBT, R. Teachers' Health. Deutsches Arzteblatt international, [s. l.], v. 112, n. 20, p. 347-356, 2015. Disponível em: https://www.ncbi.nlm.nih.gov/pubmed/26051692. Acesso em: 13 abr. 2020 .

SHUAI, J. J. et al. Assessing the effects of an educational program for the prevention of work -related musculo skeletal disorders among school teachers. BMC Public Health, [s. l.], v. 14, p. 1211, 2014. Disponível em: https://www.ncbi.nlm.nih.gov/pubmed/25422067. Acesso em: 28 set. 2020. SILVA, K. N. D.; DUTRA, F. C. M. S. E. Psychosocial job factors and chronic pain: analysis in two municipal schools in Serrana/SP. Revista Dor, [s. l.], v. 17, p. 164-170, 2016. Disponível em: http://www.scielo.br/scielo.php?script=sci_arttext\&pid=S1806$00132016000300164 \&$ nrm=iso. Acesso em: 3 abr. 2020.

SOLIS-SOTO, M. T. et al. Prevalence of musculoskeletal disorders among school teachers from urban and rural areas in Chuquisaca, Bolivia: a crosssectional study. BMC Musculoskeletal Disorder, [s. l.], v. 18, n. 1, p. 425, Oct. 2017.

https://www.ncbi.nlm.nih.gov/pmc/articles/PMC5658995/pdf/12891_201 7_Article_1785.pdf. Acesso em: 21 abr. 2020.

TEMESGEN, M. H. et al. Burden of shoulder and/neck pain among school teachers in Ethiopia. BMC Musculoskeletal Disorder, [s. l.], v. 20, n. 1, p. 18, Jan. 2019. Disponível em: https://www.ncbi.nlm.nih.gov/pmc/articles/PMC6329165/pdf/12891_201 9_Article_2397.pdf. Acesso em: 10 maio 2020.

TORRE, S. de la. Escolas Criativas: escolas que aprendem, criam e inovam. In: ZWIEREWICZ, M.; TORRE, S. de la (org.). Uma escola para o século 
XXI: escolas criativas e resiliência na educação. Florianópolis: Insular, 2009. p. 55-69.

TORRE, S. de la et al. Decálogo sobre transdisciplinaridade e ecoformação. In: TORRE, S. de la; PUJOL, M. A.; MORAES, M. C. (org.). Transdisciplinaridade e ecoformação: um novo olhar sobre a educação. Tradução de Suzana Vidigal. São Paulo: Triom, 2008. p. 21-59.

ZWIEREWICZ, M. Formação docente transdisciplinar e suas implicações no desenvolvimento de Escolas Criativas. In: GONZÁLEZ VELASCO, J. M. (org.). Transdisciplinariedad en educación: docência, escuela y aula. La Paz: Prisa. p. 173-185.

ZWIEREWICZ, M. Programa de Formação-Ação em Escolas Criativas: matizes da pedagogia ecossistêmica na formação de docentes da Educação Básica. In: DITTRICH, M. G. et al. (org.). Políticas Públicas na contemporaneidade: olhares cartográficos temáticos. Itajaí: Univali, 2017. p. 217-231.

ZWIEREWICZ, M. et al. Continued training, quality of life and prevalence of osteomuscular symptoms in teachers of Basic Education. International Journal of Development Research, [s. l.], v. 9, n. 4, p. 27391-27393, Apr. 2019. Disponível em: https://www.journalijdr.com/continued-training-quality-lifeand-prevalence-osteomuscular-symptoms-teachers-basic-education. Acesso em: 21 maio 2020.

ZWIEREWICZ, M. et al. Escolas Criativas: experiências transformadoras potencializadas na interação do Ensino Superior com a Educação Básica. Polyphonía, Goiânia, v. 27, n. 1, jan./jun. 2016.

ZWIEREWICZ, M.; TORRE, S. de la (org.). Uma escola para o século XXI: Escolas Criativas e resiliência na educação. Florianópolis: Insular, 2009.

Recebido em: 24 ago. 2020

Aceito em: 16 set. 2020 